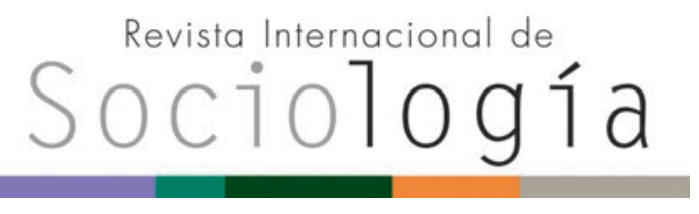

Revista Internacional de Sociología RIS

vol. 77 (1), e120, enero-marzo, 2019, ISSN-L:0034-9712 https://doi.org/10.3989/ris.2019.77.1.17.310

\section{ELECCIÓN ESCOLAR Y SELECCIÓN DE FAMILIAS: REPRODUCCIÓN DE LA CLASE MEDIA ALTA EN SANTIAGO DE CHILE}

\author{
Modesto Gayo Cal \\ Universidad Diego Portales, Chile \\ modesto.gayo@udp.cl \\ ORCID iD: https://orcid.org/0000-0003-0446-2467 \\ Gabriel Otero Cabrol \\ University of Amsterdam, The Netherlands \\ gabriel.otero@mail.udp.cl \\ ORCID iD: https://orcid.org/0000-0001-9768-5699 \\ María Luisa MÉndez \\ Universidad Diego Portales, Chile \\ marialuisa.mendez@udp.cl \\ ORCID iD: https://orcid.org/0000-0002-3493-1511
}

Cómo citar este artículo / Citation: Gayo Cal, M., G. Otero Cabrol y M. L. Méndez. 2019. "Elección escolar y selección de familias: reproducción de la clase media alta en Santiago de Chile". Revista Internacional de Sociología 77(1):e120. https://doi.org/10.3989/ ris.2019.77.1.17.310

\begin{abstract}
Resumen
La elección de colegio ha sido identificada como un momento clave en el proceso de reproducción social de la clase media alta. En Chile, en las últimas décadas, el modelo escolar ha dependido en su mayor parte, de lo que se entiende como la elección del colegio por parte de las familias. Este modelo de política pública ha convivido con la selección de los estudiantes que han hecho, a su vez, las instituciones de enseñanza. En este artículo aportamos algunos hallazgos novedosos que indican que la superación de las barreras de entrada a los colegios, principalmente a los subvencionados y privados, ha tenido una relación particularmente fuerte con la disponibilidad que las familias tienen de capital económico junto con su identificación con el catolicismo y sus prácticas religiosas. Los capitales social, cultural y educativo, junto a la clase social, también muestran diferencias importantes.
\end{abstract}

\section{Palabras Clave}

Clase media; Desigualdades educativas; Estratificación social; Modelo de elección escolar; Reproducción social.

\section{SCHOOL CHOICE AND THE SELECTION OF FAMILIES: UPPER MIDDLE CLASS REPRODUCTION IN SANTIAGO DE CHILE}

Copyright: @ 2019 CSIC. Este es un artículo de acceso abierto distribuido bajo los términos de la licencia de uso y distribución Creative Commons Reconocimiento 4.0 Internacional (CC BY 4.0).

Recibido: 01/03/2017. Aceptado: 13/07/2018

\section{Abstract}

School choice has been identified as a key moment in the process of social reproduction of the upper middle class. In Chile, over the last decades, the educational model has depended for the most part in the last decades on what is understood as parent's school choice of school. This model of public policy has coexisted with the selection that educational institutions perform in the admission process. In this article, we present some novel findings that indicate that overcoming barriers to entry to schools, mainly subsidized and private schools, has had a particularly strong relationship with the availability that families have of economic capital, along with their identification with Catholicism and their religious practices. In addition, social, cultural and educational capitals, together with social class, also show important differences.

\section{KeYWORDS}

Educational inequalities; Middle class; School choice model; Social reproduction; Social stratification. 


\section{INTRODUCCIÓN}

Estudios recientes sobre mecanismos y estrategias de reproducción de clase en los sectores privilegiados de sociedades occidentales contemporáneas (Andreotti, Le Galès y Moreno 2015; Bacqué et al, 2015; Benson et al., 2015; Raveaud and van Zanten, 2007; Reay, Crozier y James 2001) muestran que la elección escolar es para padres de clase media alta una decisión clave, ya que se estima que la influencia de la educación es central en la reproducción de la posición adquirida, constituyéndose dicha elección en un elemento clave de las estrategias de legitimación o capitalización que despliegan las familias en favor de mejorar o consolidar la posición social de sus hijos (Ball 2003; Kaufman 2005; Lareau 2011; Weis 2011).

Para el caso europeo, algunos autores (Mau 2015; Boterman 2013; Maloutas 2007; Oberti 2005) han señalado que, si bien las clases medias y medias altas actuales se habrían favorecido por las reformas de los años sesenta y setenta, hoy se encuentran en una actitud más bien defensiva, en la medida que han visto cómo el Estado ha destinado más recursos a escuelas de sectores populares y, con ello, han percibido una amenaza a su proyecto de movilidad social ascendente. Estos autores muestran cómo, al resultar difícil desde un punto de vista económico poder acceder a la educación privada, los padres y madres de clase media optan por colegios públicos, pero es en ellos donde despliegan estas diversas estrategias de clausura o cierre.

Estas investigaciones han contribuido a evidenciar que, en cuanto práctica situada, la elección escolar se ve enmarcada en contextos institucionales y culturales, es decir, en determinados sistemas educativos, estructuras sociales más o menos permeables al ascenso social, así como también en ciertos contextos de estructuración socioespacial de los recursos disponibles (esto es, una ciudad con determinados grados de segregación, barrios mixtos u homogéneos, etc.) (Carrasco, Falabella y Mendoza 2015). Autores como Bacqué et al. (2015) y Malmberg, Andersson y Bergsten (2014) han documentado las diversas estrategias desplegadas por padres y madres de clase media profesional en la elección escolar, incluso en contextos diversos (sistema público o privado predominante), mostrando que, en gran parte de los casos, estas familias tienen en cuenta (explícita o implícitamente) la composición social de las escuelas. Malmberg, Andersson y Bergsten (2014), por ejemplo, muestran cómo familias que viven en entornos predominantemente profesionales, de altos ingresos y capital cultural, tienen menos tensiones en la decisión de elegir un colegio público, mientras que familias de las mismas características que residen en barrios socioeconómica y étnicamente diversos, se inclinan por buscar colegio en lugares más distantes.
En ambos casos, la elección escolar está imbricada con lo que Andreotti, Le Galès y Moreno (2015) llaman juego de distancia y proximidad de las clases medias altas, donde no siempre se opta por la secesión y autosegregación completa, pero se prefiere tener cierto control sobre el contacto con grupos o clases sociales distintas. Esta salida parcial (partial exit) da cuenta de numerosas y variadas estrategias destinadas a escoger dimensiones de la vida donde se está dispuesto o no a compartir e interactuar con grupos sociales de menor estatus. De acuerdo con este trabajo, este juego de proximidad y distanciamiento permite seleccionar, controlar y escoger la naturaleza e intensidad de las interacciones (Andreotti, Le Galès y Moreno 2015).

Si bien la literatura se ha referido profusamente a los factores considerados en la elección escolar (por ejemplo, el desempeño académico del colegio, la composición socioeconómica del estudiantado, el precio o la distancia entre el hogar y la escuela), un aspecto que resulta especialmente notorio es que padres y madres de sectores medio-altos evalúan los impactos de largo plazo que la escuela tiene en la futura posición social del niño o niña y, en dichos términos, esta es vista como una institución de reproducción o eventual ascenso social (Carrasco, Falabella y Mendoza 2015). Estas estrategias tienen resonancia con los hallazgos para el caso de familias de clase media en Chile, donde también se privilegian ciertos colegios para reproducir la posición de clase de los padres resguardando las orientaciones culturales de las familias; evitar o reducir el contacto con familias de otras clases sociales; optar por el mejor colegio, aunque éste esté lejos del lugar de residencia; enfrentar tensiones entre ser un buen padre o un buen ciudadano, o elegir en función de las experiencias escolares de los propios padres (Carrasco, Falabella y Mendoza 2015; Raczynski y Hernández 2011; BeIlei 2007; Thieme y Treviño 2011, entre otros).

El sistema educacional chileno ha venido funcionado históricamente con base en un modelo de elección escolar, lo que ya varias décadas atrás, previo al gobierno de la Unidad Popular y la dictadura, permitía a cualquier familia elegir el colegio que deseaba para sus hijos, si bien en la práctica esta decisión era un aspecto secundario en comparación con la importancia de la oferta (Carrasco, Donoso y Mendoza 2016a). Viniendo de este contexto anterior, se puede entender que la elección, ya operativa pero de menor eficacia, fue potenciada el año 1981 con la implementación de un programa de incentivos para la educación privada mediante vouchers, bajo el supuesto de ineficiencia asociado a las escuelas públicas (Hsieh y Urquiola 2006). Desde entonces, se ha observado una disminución considerable de la educación estatal y una expansión mayoritaria de la educación subvencionada que, en la actualidad, representa cerca del $55 \%$ de todo el sistema. 
Luego de 35 años de funcionamiento, los hallazgos recientes muestran una serie de consecuencias negativas de este modelo educativo, como una mayor segregación educativa, objeciones respecto del manejo de información por parte de los padres, junto con diferencias importantes en torno a las preferencias de elección de tipo académica, según el nivel económico (Contreras, Sepúlveda y Bustos 2010; Elacqua 2012; Thieme y Treviño 2011; Verger, Bonal y Zancajo 2016). Asimismo, el caso de Chile y, más específicamente, de Santiago (donde se desarrolla el presente estudio) es particularmente explícito, pues el modelo económico neoliberal implementado progresivamente desde mediados de los años setenta ha implicado una privatización prácticamente absoluta de servicios básicos como la vivienda, la educación y las pensiones, teniendo profundas consecuencias en la estratificación de la sociedad chilena. Esto se refleja en los marcados patrones de segregación periférica y concentración espacial de la riqueza en el cono de alta renta (Méndez y Gayo 2019).

Por lo tanto, la elección debe ser entendida como un mecanismo situado en un contexto social, económico y espacial: los colegios no están ajenos a esta imbricación, es decir, su oferta también responde a dichas dinámicas sociales. La oferta escolar se caracteriza por la selección que realizan los colegios, produciendo como resultado la adecuación socioeconómica e ideológica entre la demanda por parte de los padres y madres, por un lado, y la oferta situada que los colegios ofrecen, por otro. En este artículo argumentamos que este encaje es un aspecto central en la consolidación de un sistema que ha potenciado la reproducción social, en especial de la clase media alta.

En síntesis, el acto de elegir no es materia exclusiva de los padres, sino que las escuelas utilizan criterios de admisión para seleccionar a las familias y estudiantes, los cuales se constituyen en efectivas barreras de entrada que operan necesariamente como mecanismos de selección y, eventualmente, de segregación (Carrasco, Gutiérrez y Flores 2017). Por lo tanto, el modelo chileno de school choice se basa en la convergencia entre la elección que las familias, principalmente de clase media alta, hacen de los colegios $y$, simultáneamente, en la elección que éstos hacen de las primeras. De ese modo, a través de la elección, se produce un ajuste más o menos satisfactorio entre demanda (familias) y oferta (centros escolares) 1 . En dicha coincidencia, institucionalizada de acuerdo con la estructura social, se encuentra un momento clave de la segregación escolar y espacial y, en definitiva, de la reproducción de clase en Chile. La investigación sobre las desventajas o efectos nocivos del sistema educativo ha sido abundante, pero más reducido el tratamiento del momento mismo de la elección, pilar de todo el modelo ${ }^{2}$. En este artículo buscamos contribuir a mejorar la comprensión de este proceso atendiendo a un aspecto crucial involucrado en la elec- ción: los requerimientos solicitados por las escuelas, principalmente las particulares privadas y subvencionadas (vouchers). Este momento es especialmente interesante para delimitar consecuencias distintivas del llamado modelo de school choice porque permite entender cómo efectivamente funciona una forma de elección que presenta dos facetas diferentes y, al mismo tiempo, convergentes en el resultado final.

Utilizando datos de dos encuestas realizadas en Santiago de Chile, la presente investigación propone que los criterios de admisión en los colegios funcionan como mecanismos eficaces para la reproducción de clase. De forma más detallada, podemos resumir las contribuciones de este estudio en los puntos siguientes. Primero, además de estudiar la población general de la capital chilena, profundizamos en un grupo poco explorado en la literatura como es la clase media alta, cuya reproducción tiene efectos en todo el sistema. Segundo, estudiamos mecanismos de selección que no han sido incluidos en investigaciones previas, usualmente basadas en datos del cuestionario de padres del Sistema de Medición de la Calidad de la Educación (SIMCE) (Contreras, Sepúlveda y Bustos 2010; Madero y Madero 2012) o, más recientemente, en una encuesta a profesores (Carrasco, Gutiérrez y Flores 2017). En particular, agregamos requisitos de admisión novedosos como son provenir de una familia cercana a una congregación religiosa, ser descendiente de la comunidad asociada al colegio, disponer de cartas de recomendación y comprar acciones. Esto permite profundizar de forma más exhaustiva en la comprensión de las barreras de entrada a los colegios, sobre todo en los sectores medios altos, y así entender con mayor claridad cómo se configura la segregación del sistema educativo. Tercero, nos enfocamos en el momento mismo de la elección, a diferencia de los estudios preocupados por las preferencias de elección (Carrasco, Donoso y Mendoza 2016a; Carrasco, Falabella y Tironi 2016b; Flores y Carrasco, 2016), en los cuales el proceso de formación de la decisión familiar es un tema central. Esto es importante porque alude más bien a la interrelación que se produce entre familias y escuelas, entre oferta y demanda. En efecto, nos ayuda a reflexionar respecto a si, efectivamente, las escuelas segregan por sí mismas o bien forman parte de un entramado social que hace posible la estratificación. Cuarto, para capturar las características de la demanda (familias), accedemos a distintas formas de capital, no sólo económico, sino también social y cultural. Estos dos últimos recursos, por lo general, se encuentran ausentes en la literatura académica que domina el debate, lo que restringe nuestra capacidad para entender los procesos de selección. Desde la sociología se sabe que las familias tienden a movilizar los distintos capitales disponibles para darle forma a las diferencias de clase (Bourdieu y Passeron 1990; Lareau 2011), y la selección de colegio es un momento clave en este proceso. 


\section{EL MODELO SCHOOL CHOICE Y LA POSIBILIDAD DE DECIDIR}

Los defensores del modelo school choice conciben los arreglos de mercado como la mejor opción para aumentar la eficacia escolar (Chubb y Moe 1990) o como un esfuerzo por reestructurar la educación pública, pensada esencialmente ineficiente. Esto con la finalidad de igualar las oportunidades de los estudiantes y promover la justicia social, más aun teniendo en cuenta que la elección ha sido una práctica restringida a las familias más adineradas a través del sistema educacional privado (Klees 2008; Ryan y Heise 2002).

Durante el periodo de dictadura militar (19731990), se implementaron en Chile una serie de reformas en el sistema escolar que siguieron la lógica del modelo de elección escolar. Dentro de las principales políticas se incluyeron la transferencia de la administración de colegios públicos a las municipalidades, el permiso de apertura de nuevas escuelas privadas y la creación de un sistema de vouchers para financiar la provisión de educación primaria (Hsieh y Urquiola 2006; Thieme y Treviño 2011). A partir de esta transformación el sistema quedó conformado por tres tipos de escuelas, en función de sus formas de financiamiento: públicas, las cuales reciben un pago estatal por cada estudiante y son controladas por el Ministerio de Educación; subvencionadas (vouchers), que son administradas por privados con financiamiento compartido entre el Estado y los padres, y privadas, especialmente orientadas hacia la población más adinerada, las cuales son costeadas exclusivamente por los padres.
En la práctica, las reformas implementadas en Chile han generado cambios significativos en el mercado educacional. Si bien en la década de 1970 la proporción de escuelas públicas oscilaba alrededor del $80 \%$, desde la década de 1980 tal representación se ha reducido drásticamente hasta alcanzar aproximadamente el $35 \%$ en el año 2018. Por el contrario, las escuelas subvencionadas han aumentado claramente su participación cubriendo más del $55 \%$ de la matrícula de todo el sistema escolar. Por su parte, los colegios privados sin subsidio estatal han mantenido una matrícula constante en torno al 9 $\%$ (véase la figura 1).

\section{ELECCIÓN ESCOLAR Y RESULTADOS EDUCA- TIVOS}

Aunque los hallazgos muestran que los efectos de la elección escolar a través de una política de vouchers dependen del diseño, el tipo de aplicación, el tiempo de implementación y las condiciones de elección (Verger, Bonal y Zancajo 2016), cada vez existe mayor certeza para afirmar que las elecciones reales que derivan de esta lógica de mercado en la educación representan importantes mecanismos de reproducción intergeneracional de la desigualdad social (Borman y Dowling 2010; Lubienski, Weitzel y Lubienski 2009). En efecto, se han estimado diferencias importantes en torno a las preferencias de elección según el nivel socioeconómico o la clase social de las familias. Según se indica, mientras los padres de estrato o clase media se presentan como agentes activos de elección, los más desaventajados se muestran como

Figura 1.

Porcentajes nacionales de inscripción por tipo de dependencia de las escuelas, 1970-2015. Elaboración sobre base de datos del Ministerio de Educación ${ }^{3}$

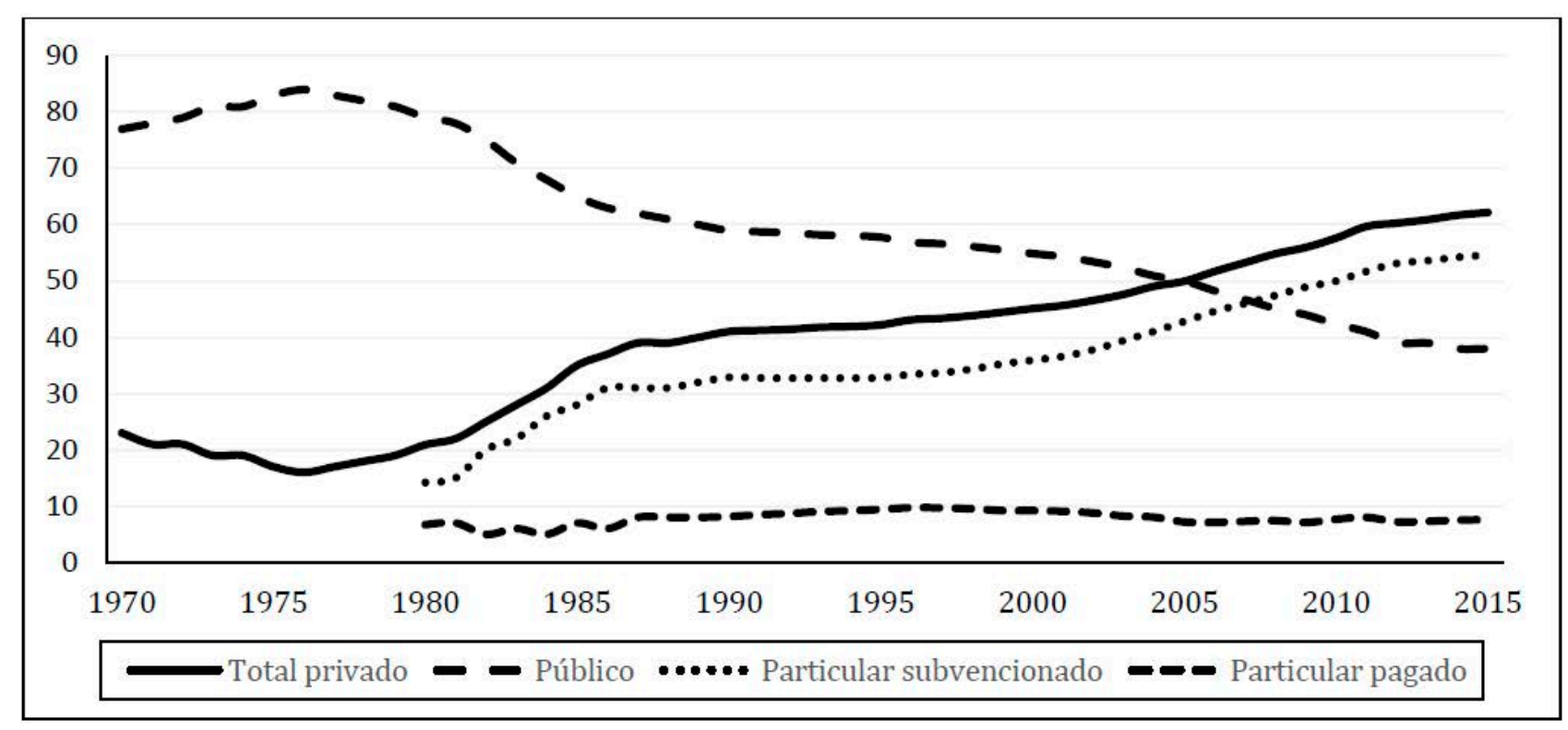

RS [online] 2019, 77 (1), e120. REVISTA INTERNACIONAL DE SOCIOLOGÍA. ISSN-L: 0034-9712 
actores más pasivos y orientados más localmente (Ball 2003; Burgess et al. 2015). Asimismo, esta evidencia demuestra que las competencias académicas suelen ser mucho más valoradas por los padres de altos ingresos, lo que limita el alcance del supuesto de elección y competencia. En la práctica, los estudiantes de colegios subvencionados (vouchers) muestran un rendimiento académico más alto que sus pares de escuelas públicas en la mayoría de la evidencia disponible (Mizala y Torche 2012; Otero, Carranza y Contreras 2017; Thieme, Prior y Tortosa-Ausina 2013), especialmente cuando acceden a escuelas administradas por sostenedores asociados a la Iglesia católica (Contreras, Sepúlveda y Bustos 2010; Madero y Madero 2012). Asimismo, en línea con la evidencia internacional, en Chile la variabilidad de preferencias en el proceso de elección se asocia de manera decisiva con el nivel socioeconómico. Estudios cualitativos recientes muestran que, pese a las fuertes campañas desarrolladas por las autoridades para incentivar las preferencias de elección en torno a resultados académicos, las racionalidades de los padres parecen ir más allá de los test estandarizados tipo SIMCE (Verger, Bonal y Zancajo 2016). Mientras en las familias más vulnerables las preferencias se ven influidas mayormente por la cercanía, en las familias con un estatus socioeconómico alto los resultados educativos y valores asociados a la religión de las escuelas aparecen como criterios más importantes para la elección. Por ejemplo, Flores y Carrasco (2016) destacan cómo las familias de religión evangélica tienden a elegir colegios de peor rendimiento SIMCE. Asimismo, se sostiene que la elección de colegio, principalmente en la clase media alta, tiene que ver con una decisión estratégica conveniente para el desarrollo de redes sociales que probablemente traerán beneficios futuros para sus miembros (Méndez y Gayo 2019).

\section{Selección de familias POR LAS ESCUELAS}

Muchos estudios internacionales muestran que las características socioeconómicas de los estudiantes y la entrega de información sobre el rendimiento de las escuelas produce cambios en las elecciones que hacen las familias, especialmente en las más desfavorecidas (Hastings y Weinstein 2007). Sin embargo, cada vez más la literatura ha comenzado a destacar las restricciones impulsadas por el modelo de elección escolar, en buena medida por los criterios de admisión que despliegan las escuelas (proceso de selección) (Musset 2012) y su relación con las prácticas realizadas por las familias (Gessaghi y Méndez 2015). Se supone que la elección, como práctica simbólicamente situada a partir de características socioculturales, ha derivado en un proceso de autosegregación en el cual las familias de distintas clases sociales pue- den ser objeto de exclusión y, asimismo, aparecer como agentes activos de la misma (Carrasco, Falabella y Mendoza 2015).

Para el caso chileno, las investigaciones han descrito tres tipos de criterios de admisión presentes en el proceso de selección: de tipo académico (test de habilidades cognitivas), de tipo económico (certificado de remuneraciones) y de carácter religioso (certificados de matrimonio y bautizo) (Contreras, Sepúlveda y Bustos 2010; Madero y Madero 2012; Moya y Hernández 2014). Hablamos de mecanismos de clasificación que difieren sustancialmente de acuerdo al tipo de establecimiento y que están bastante extendidos en las instituciones asociadas al programa de vouchers, pese a tratarse de una práctica ilegal en el nivel primario (Carrasco, Gutiérrez y Flores 2017; Verger, Bonal y Zancajo 2016). A este respecto, los autores se refieren a procesos de selección cuyo objetivo se traduce en obtener estudiantes con mejor origen socioeconómico y, de esa forma, mejorar los resultados de las escuelas (Contreras, Sepúlveda y Bustos 2010; Hsieh y Urquiola 2006). En la práctica, algunos estudios han constatado que los niños que estudian en colegios donde se emplean mecanismos de selección en función de las habilidades de los estudiantes y requisitos religiosos tienen un rendimiento académico por encima de aquellos que acceden a escuelas sin ningún dispositivo de exclusión (Contreras, Sepúlveda y Bustos 2010). Dicho de otra forma, se ha sostenido que estas formas de reclutamiento son las principales causantes del alto rendimiento académico exhibido por las escuelas privadas en Chile (Hsieh y Urquiola, 2006). En otros términos, la selección de los estudiantes por parte de las escuelas es causante principal de sus logros institucionales $y$, adicionalmente, consolida el nivel educativo de partida, reproduciendo el origen en el destino, es decir, ayudando grandemente a la transmisión de las posiciones de clase.

\section{Metodología y datos}

Para la realización de este estudio se utilizaron datos primarios de una encuesta cara a cara realizada con el propósito de estudiar las barreras, prácticas y costos de la reproducción de la posición de la clase media alta en Santiago de Chile. La encuesta analiza información de dos muestras probabilísticas representativas de parejas con, al menos, un hijo en edad escolar o mayor que reside en (i) alguna de las cinco comunas más ricas de la ciudad, del denominado barrio alto o cono de alta renta (Agostini et al. 2016); o (ii) en cualquier comuna del Gran Santiago, respectivamente. La primera muestra se compone de 400 familias, con un error muestral de 4,9\%. La segunda reúne a 800 familias, con un error muestral de $3,5 \%$. En ambos casos se implementó un muestreo multie- 
tápico por estratos (comunas), conglomerados de manzanas, viviendas y, finalmente, personas jefas de hogar o parejas de las mismas. La encuesta fue financiada por el Fondo Nacional de DesarroIlo Científico y Tecnológico (FONDECYT) e implementada durante el segundo semestre de 2015 por la empresa Datavoz.

Con respecto a las principales variables estudiadas, una batería de doce preguntas recoge información sobre los requisitos que los padres tuvieron que enfrentar para poder matricular a sus hijos en el colegio de su elección (ver tabla II). La pregunta general de la que derivan estos ítems es la siguiente: ¿Cuáles de los siguientes requisitos o antecedentes le fueron solicitados cuando se matriculó al estudiante en este establecimiento? Las respuestas afirmativas fueron codificadas con el valor '1', mientras que las negativas con el valor ' 0 '.

En segundo lugar, un conjunto de variables permiten poner a prueba nuestra hipótesis de investigación (ver tabla I), es decir, si efectivamente los requisitos de entrada a los colegios están asociados con diferentes grados de concentración de capital económico y nivel educativo, tal y como han mostrado varios de los estudios mencionados previamente. A ello le hemos agregado un indicador de capital social, pues ello también apuntaría a que el fenómeno de las barreras empleadas por los colegios pudiera estar vinculado a la pertenencia o disponibilidad de redes sociales (Carrasco, Falabella y Tironi 2016b). Además, incluimos algunas variables adicionales que pudieran estar afectando la elección de colegio: rango de edad del encuestado, tipo de colegio al que asiste su hijo/a, identificación política, religión católica y asistencia a la Iglesia.

El indicador de capital social se refiere a la cantidad de oficios u ocupaciones de alto prestigio en las que se desempeñan personas cercanas al encuestado. Por ejemplo, médicos, abogados, periodistas o escritores, sociólogos o antropólogos, directores generales, ingenieros comerciales, profesores de universidades, arquitectos y psicólogos. Estas ocupaciones quedaron agrupadas mediante un Análisis de Componentes Principales (ACP) realizado sobre la muestra general, que incluyó otras ocho ocupaciones. Esta medida de capital social deriva de un instrumento denominado "generador de posiciones" (Lin 2008), el cual es considerado un buen indicador de los recursos que se encuentran asociados a las redes sociales de las personas (Van der Gaag, Snijders y Flap 2008) y que ha sido utilizado en varios estudios influyentes en el área (Erickson 1996; Flap y Boxman 2001). La información se captura preguntándole a los encuestados si conocen o no a alguien que tenga una ocupación determinada. En nuestro caso la pregunta fue: ¿tiene algún amigo/a cercano que tenga alguna de las siguientes profesiones u oficios? Cuando se incluye una cantidad importante de ocupaciones, con distintos niveles de prestigio y poca dispersión en cuanto al ingreso que se obtiene de ellas, se pueden realizar estimaciones sobre la diversidad de la red. También se pueden contar las ocupaciones con un nivel de prestigio alto para representar particularmente la movilización del capital social, que es precisamente lo que hacemos en este estudio. Por su parte, la medida de capital cultural corresponde a un promedio ponderado y diferenciado para las dos muestras, calculado con base en siete prácticas culturales: leer un libro completo, ir al cine, ir al teatro, ir a museos, ir a conciertos de música pop o rock, ir a conciertos de orquestas u ópera y visitar sitios históricos. La clase social deriva del esquema de clases oficial del Reino Unido, elaborado por la National Statistics Socio-Economic Classification (NS-SEC), basada en el Standard Occupational Classification 2010 (SOC 2010) y que clasifica a las personas en función de su estatus ocupacional. Para este estudio hemos usado la desagregación de clases sociales en tres grupos, con base en el número de casos de los que disponíamos. Segundo, para el nivel educacional se utiliza el formato desarrollado por el International Standard Classification of Education (ISCED), que permite generar categorías estandarizadas y comparables. La variable de capital económico es un indicador de los bienes y servicios disponibles en el hogar, ponderado en función de la tenencia y calculado sobre la muestra general. Se incluyen diecisiete ítems: nevera, lavadora automática de platos, secadora automática de ropa, servicio doméstico, cámara de video, automóvil de los últimos tres años, cuenta bancaria, refrigerador de dos puertas, tina de baño, teléfono fijo, $d v d$, horno microondas, casa de USD150.000 o más, local comercial, terreno o campo, segunda casa o departamento y casa de vacaciones. El puntaje máximo definido fue de 1000 puntos. Se trata de un indicador que tiene una alta correlación con el ingreso del hogar $(r=0.543$ en la muestra de alta renta y $r=0.752$ en la muestra general). Esta última variable se excluye de los análisis porque cuenta con una alta frecuencia de valores sin respuesta. Los estadísticos descriptivos y definiciones de las variables se presentan en la tabla I. Cabe precisar que, con el objetivo de facilitar la lectura de las tablas, la muestra que representa al barrio alto de la ciudad ha sido denominada 'alta renta', mientras que aquella representativa de todo Santiago ha sido definida como 'general'. La posibilidad de comparar nos permitió tener una mirada mucho más certera sobre lo que ha estado sucediendo en la clase media alta, que era finalmente la muestra que estaba en el centro del estudio, permitiéndonos entender mejor algunas de sus características específicas. 
Tabla I

Variables independientes y análisis descriptivo univariado

\begin{tabular}{|c|c|c|c|c|c|c|c|c|c|}
\hline \multirow{3}{*}{$\begin{array}{l}\text { Variables } \\
\text { Tipo de escuela }\end{array}$} & \multirow[t]{3}{*}{ Categorías } & \multicolumn{8}{|c|}{ Media/porcentaje } \\
\hline & & \multicolumn{4}{|c|}{ Muestra de alta renta } & \multicolumn{4}{|c|}{ Muestra general } \\
\hline & & Pública & Subv. & Privada & Total & Pública & Subv. & Privada & Total \\
\hline \multicolumn{10}{|l|}{$\begin{array}{l}\text { Variables } \\
\text { independientes }\end{array}$} \\
\hline \multirow[t]{4}{*}{ Edad } & $18-39$ & 3,83 & 18,37 & 16,08 & 15,63 & 12,51 & 25,73 & 17,52 & 18,09 \\
\hline & $40-49$ & 11,48 & 14,25 & 15,68 & 14,99 & 17,33 & 21,65 & 15,19 & 18,70 \\
\hline & $50-59$ & 11,48 & 31,10 & 19,27 & 21,50 & 25,15 & 24,20 & 20,36 & 24,21 \\
\hline & $>59$ & 73,22 & 36,28 & 48,97 & 47,89 & 45,01 & 28,42 & 46,93 & 38,99 \\
\hline \multirow[t]{3}{*}{ Tipo de escuela } & Pública & - & - & - & 8,19 & - & - & - & 50,27 \\
\hline & Subvencionada (referencia) & - & - & - & 24,18 & - & - & - & 37,68 \\
\hline & Privada & - & - & - & 67,63 & - & - & - & 12,05 \\
\hline \multirow[t]{4}{*}{$\begin{array}{l}\text { Clase social (SOC } \\
\text { 2010) }\end{array}$} & Altos ejecutivos/profesionales & 17,22 & 62,11 & 63,89 & 59,64 & 10,93 & 23,72 & 47,87 & 20,20 \\
\hline & Ocupaciones intermedias & 55,08 & 30,45 & 23,79 & 27,96 & 29,80 & 38,55 & 20,66 & 32,00 \\
\hline & Trabajadores manuales/rutinarios & - & - & - & - & 36,36 & 23,81 & 10,69 & 28,54 \\
\hline & Nunca ha trabajado & 27,70 & 7,44 & 12,32 & 12,40 & 22,91 & 13,92 & 20,78 & 19,26 \\
\hline Educación & Código ISCED & 3,75 & 4,34 & 4,70 & 4,54 & 2,05 & 2,74 & 3,85 & 2,53 \\
\hline Capital social & $\begin{array}{l}\text { Conocer personas de nueve } \\
\text { ocupaciones de alto prestigio } \\
\text { (variable contador) }\end{array}$ & 4,47 & 6,47 & 6,78 & 6,52 & 1,48 & 2,52 & 5,11 & 2,31 \\
\hline Capital cultural & $\begin{array}{l}\text { Índice promedio de ocho } \\
\text { prácticas culturales }\end{array}$ & 2,70 & 4,51 & 3,78 & 3,87 & 1,41 & 2,04 & 3,17 & 1,86 \\
\hline Capital económico & $\begin{array}{l}\text { Puntaje de dieciocho bienes y } \\
\text { servicios }\end{array}$ & 440,80 & 594,98 & 594,27 & 581,88 & 123,85 & 195,66 & 338,16 & 176,73 \\
\hline \multirow[t]{5}{*}{ Identificación política } & Izquierda & 17,82 & 13,43 & 13,93 & 14,13 & 22,10 & 20,82 & 25,34 & 22,01 \\
\hline & Centro izquierda & 11,48 & 24,03 & 13,14 & 15,64 & 9,03 & 13,03 & 18,27 & 11,65 \\
\hline & Centro derecha & 5,74 & 9,38 & 13,47 & 11,85 & - & - & - & - \\
\hline & Derecha & 9,56 & 20,59 & 15,41 & 16,18 & 4,31 & 7,01 & 12,84 & 6,35 \\
\hline & Sin identificación política & 55,40 & 32,56 & 44,05 & 42,20 & 64,57 & 59,14 & 43,55 & 59,99 \\
\hline \multirow[t]{2}{*}{ Religión católica } & No (referencia) & 5,74 & 33,14 & 20,65 & 22,45 & 40,34 & 35,52 & 27,61 & 36,99 \\
\hline & Sí & 94,26 & 66,86 & 79,35 & 77,55 & 59,66 & 64,48 & 72,39 & 63,01 \\
\hline \multirow[t]{2}{*}{ Práctica religiosa } & No (referencia) & 32,02 & 40,54 & 34,73 & 35,91 & 55,12 & 51,36 & 45,91 & 52,59 \\
\hline & Sí & 67,98 & 59,46 & 65,27 & 64,09 & 44,88 & 48,64 & 54,09 & 47,41 \\
\hline Observaciones & & 34 & 95 & 271 & 400 & 389 & 314 & 97 & 800 \\
\hline
\end{tabular}

\section{RESULTADOS}

La presentación de los hallazgos se hará en dos partes. En la primera exponemos la frecuencia de la exigencia de un amplio conjunto de requisitos para poder cumplir con las condiciones mínimas de entrada a los colegios. Para ello, distinguimos entre colegios públicos, subvencionados y privados. Además, describimos la diferencia entre las familias de clase media alta del cono de alta renta y las familias del conjunto de la Región Metropolitana. En la segunda parte vamos más allá de los requisitos (o de la oferta escolar) para estudiar su asociación con varia- bles sociales y económicas (el lado de las familias o la demanda). Ello nos permitirá entender la función social que cumple cada uno de los requisitos en la reproducción social de clase.

\section{Requisitos de entrada a los colegios}

En nuestra encuesta recogimos un amplio conjunto de requisitos contemplados por muchos de los colegios como un elemento necesario en la evaluación de los candidatos (ver tabla II). Son de naturaleza muy variada, yendo desde el certificado de evaluación de educación preescolar hasta la compra de 
acciones, pasando por la entrega de certificados de matrimonio civil o de remuneraciones, entre otros. En conjunto, se puede observar que los colegios públicos solicitan menos certificaciones que los colegios subvencionados y privados. Además, cuando se produce dicha solicitud, se concentran sobre todo en los certificados de notas, la entrevista con los padres y el examen escrito. Asimismo, se observa la tendencia a solicitar más requisitos en los colegios del sector noreste o cono de alta renta (ver fila 'PROM' en la tabla II), aunque las diferencias dependerán del tipo de barrera de acceso de la que estemos hablando, situándose en el extremo por su alta intensidad o razón la petición de cartas de recomendación en los colegios subvencionados y la compra de acciones en los colegios privados.

Podríamos hablar de tres tipos de requisitos:

1. Requisitos menos exclusivos y excluyentes, en cuanto se trata de exigencias que tienden a ser solicitadas de manera bastante transversal por los colegios. Este grupo incluye la evaluación de la educación preescolar, el certificado de notas del establecimiento anterior, las entrevistas con padres, el examen escrito y la participación del niño en una sesión de juego. Es precisamente con base en este tipo de requisitos que el estudio de Carrasco, Gutiérrez y Flores (2017) muestra evidencia que indica que los colegios más selectivos son los privados, seguidos de los subvencionados $\mathrm{y}$, finalmente, están los públicos o estatales, con diferencias bien definidas entre los tres. Es decir, estudian las diferencias de acuerdo a lo que podríamos entender como una línea base o mínima de distinción, pero igualmente les sirve para hallar una importante diversidad.

2. Requisitos permeados por obligaciones de índole religiosa. Los requerimientos incluyen provenir de una familia cercana a la congregación religiosa a la que está vinculado el colegio, el certificado de matrimonio civil, ser descendiente de la comunidad asociada al colegio, el certificado de remuneraciones y un certificado de bautismo o matrimonio eclesiástico. Dentro de este grupo, destacan las similitudes que encontramos entre los colegios subvencionados y privados, lo que visibiliza el importante papel de las instituciones de congregación eclesiástica en el sistema escolar destinado a las familias de nivel socioeconómico alto y medio. Cabe subrayar aquí, como en el conjunto de este análisis, que son menores las diferencias entre los colegios privados y subvencionados, situados ambos frente a los de propiedad pública o estatal.

3. Requisitos exclusivos como cartas de recomendación y compra de acciones, las cuales ponen en evidencia formas de clausura y cierre de grupo con base en el capital social y los recursos económicos, mostrando nuevamente que las barreras más elevadas de entrada están presentes en el sector noreste de la capital.

Tabla II

Requisitos de admisión por tipo de escuela

\begin{tabular}{|c|c|c|c|c|c|c|c|c|c|c|c|c|}
\hline & \multicolumn{4}{|c|}{ Escuelas públicas } & \multicolumn{4}{|c|}{ Escuelas subvencionadas } & \multicolumn{4}{|c|}{ Escuelas privadas } \\
\hline & Alta & Gral. & GAP & RATIO & Alta & Gral. & GAP & RATIO & Alta & Gral. & GAP & Ratio \\
\hline A & 15,3 & 30,8 & $-15,5$ & 0,5 & 55,9 & 41,9 & 14,1 & 1,3 & 41,6 & 51,5 & $-9,9$ & 0,8 \\
\hline B & 49,8 & 37,5 & 12,4 & 1,3 & 80,7 & 54,9 & 25,8 & 1,5 & 46,5 & 59,3 & $-12,8$ & 0,8 \\
\hline C & 57,5 & 52,9 & 4,6 & 1,1 & 96,9 & 73,1 & 23,8 & 1,3 & 94,0 & 78,6 & 15,3 & 1,2 \\
\hline D & 53,7 & 35,3 & 18,4 & 1,5 & 80,3 & 62,8 & 17,5 & 1,3 & 75,1 & 56,4 & 18,7 & 1,3 \\
\hline E & 18,6 & 15,8 & 2,8 & 1,2 & 67,6 & 40,0 & 27,6 & 1,7 & 56,2 & 31,7 & 24,5 & 1,8 \\
\hline$F$ & 1,9 & 2,9 & $-1,0$ & 0,7 & 32,3 & 13,6 & 18,6 & 2,4 & 18,1 & 13,1 & 5,1 & 1,4 \\
\hline G & 21,0 & 16,6 & 4,5 & 1,3 & 65,0 & 32,2 & 32,8 & 2,0 & 70,6 & 39,5 & 31,1 & 1,8 \\
\hline H & 1,9 & 3,8 & $-1,8$ & 0,5 & 45,9 & 16,9 & 29,0 & 2,7 & 24,4 & 17,2 & 7,1 & 1,4 \\
\hline I & 1,9 & 6,5 & $-4,6$ & 0,3 & 37,7 & 21,3 & 16,4 & 1,8 & 47,2 & 22,5 & 24,7 & 2,1 \\
\hline $\mathbf{J}$ & 17,2 & 9,2 & 8,0 & 1,9 & 71,2 & 27,0 & 44,2 & 2,6 & 62,5 & 36,6 & 25,9 & 1,7 \\
\hline K & 1,9 & 2,8 & $-0,9$ & 0,7 & 37,7 & 6,8 & 31,0 & 5,6 & 27,8 & 16,0 & 11,9 & 1,7 \\
\hline L & 0,0 & 0,0 & 0,0 & - & 10,4 & 4,0 & 6,3 & 2,6 & 30,8 & 3,1 & 27,6 & 9,8 \\
\hline PROM. & 2,4 & 2,2 & - & - & 6,8 & 3,9 & - & - & 5,9 & 4,3 & - & - \\
\hline
\end{tabular}

Nota: La tabla muestra qué porcentaje de la muestra responde que 'Sí' en cada requisito, con excepción del promedio de requerimientos solicitados (PROM). A: evaluación de educación preescolar, B: certificado de notas del establecimiento anterior, C: entrevista con los padres, D: examen escrito, E: sesión de juego, F: provenir de una familia cercana a la congregación religiosa, G: certificado de matrimonio civil, $\mathrm{H}$ : ser descendiente de la comunidad asociada al colegio, I: certificado de remuneraciones, J: certificado de bautizo o matrimonio por la Iglesia, K: cartas de recomendación, L: compra de acciones. 


\section{Las familias que superan las barreras de entrada}

El efecto de los requisitos de entrada a los colegios no es azaroso. En este apartado demostramos cómo dichas exigencias operan como barreras efectivas que colaboran en el encaje entre la oferta y la demanda educativa, dotando a los colegios de herramientas para elegir a su público y a las familias de una ayuda para encontrar espacios educativos homogéneos y, por lo tanto, excluyentes. Si en la obra de Pierre Bourdieu los colegios legitimaban las desigualdades de origen, reconociendo y respaldando la transmisión inconsciente de capital cultural que había tenido lugar previamente en las familias (Bourdieu y Passeron 1990), en Chile, de forma diferente, los colegios emplean dispositivos perfectamente racionalizados que colaboran en la reproducción consciente de las clases sociales (Carrasco, Falabella y Mendoza 2015).

Esta conclusión adelantada proviene de la lectura de las tablas III y IV, las cuales muestran los resultados de una serie de modelos de regresión logística binaria para las dos muestras analizadas. Las variables dependientes tienen una distribución binomial, producto de la exigencia o no de cada uno de los criterios mencionados en el apartado previo. Cabe precisar que para la muestra general no se calculó el modelo que estima el requisito de compra de acciones, porque la variable respuesta cuenta con pocos encuestados con hijos en este tipo de colegios $(n=27)$, los cuales suelen estar situados en áreas de altos ingresos. En relación con cada una de las variables independientes, las tablas presentan los coeficientes logarítmicos (logaritmo natural de la razón), los errores estándar entre paréntesis y los niveles de significación de la diferencia. Los modelos están ordenados desde los requisitos de admisión más comunes (certificado de notas, entrevista con los padres, entre otros) hasta los más exclusivos (cartas de recomendación y compra de acciones).

Para partir analizando lo que sucede al conjunto de la población de forma más transversal, en primer lugar, nos enfocamos en analizar los resultados de la muestra representativa de la Región Metropolitana, mencionando únicamente las variables que tienen efectos significativos. A este respecto, la tabla III muestra que las familias que acceden a colegios privados $y$, sobre todo, públicos deben enfrentar en menos ocasiones la solicitud de la mayoría de los requisitos descritos, en comparación con aquellas que postulan a colegios particulares subvencionados. Esto ocurre no sólo con barreras comunes como el examen escrito a los estudiantes y el matrimonio civil de los padres, sino también respecto a unos más distintivos, como el certificado de remuneraciones y ser descendiente de la comunidad asociada al colegio. En segundo lugar, el nivel educacional y el posicionamiento político muestran generalmente una débil relación con los requisitos de admisión escolar y, cuando esa relación se da, es más bien negativa, lo que podría indicar una distribución bastante homogénea dentro del sistema educativo general. En tercer lugar, los capitales social y, sobre todo, cultural y económico de las familias demuestran afectar positivamente la superación de barreras de entrada a los colegios. En otros términos, estos capitales parecen constituirse como un elemento estratégico clave en el momento de enfrentar los obstáculos impuestos por las instituciones escolares. Entre los dos últimos, es importante destacar que es el capital económico el que aparece como el factor más generalizado y, por tanto, más necesario. Finalmente, las creencias y el comportamiento religioso de los padres tienen una importancia significativa en la satisfacción de ciertos criterios de selección. En concreto, se relaciona con criterios moderadamente excluyentes, como la entrevista con padres y, como resulta esperable, con requisitos más distintivos, como los certificados de bautizo y matrimonio por la Iglesia, el certificado de matrimonio civil y el hecho de provenir de una familia cercana a la congregación religiosa del colegio. En resumen, tomando en consideración que se trata de una muestra en la que son escasas las familias que envían a sus hijos a colegios privados y que son los colegios subvencionados los que son manifiestamente más proclives a exigir requisitos de entrada, nos encontramos que son principalmente los padres que matriculan a sus hijos en estos últimos colegios los que deben disponer de una combinación de capitales social, cultural y económico y, asimismo, tener un comportamiento religioso para superar las barreras que deben ser sorteadas para escolarizar a sus hijos en la institución de su elección.

Cuando atendemos a los resultados para la muestra de altos ingresos, nos encontramos con similitudes y diferencias con respecto al análisis previo (ver tabla IV). La evidencia indica que el tipo de colegio aparece recurrentemente como un predictor significativo. En este caso, los colegios públicos son utilizados por un porcentaje muy reducido de las familias de la muestra, por lo que fueron agrupados junto a los colegios subvencionados para representar la categoría de referencia. Al igual que sucedía con la muestra general, nuevamente los padres que eligen colegios privados se ven menos expuestos a la exigencia de requisitos que aquellos que optan por colegios subvencionados, aunque la situación es mucho más pareja que para el conjunto de la Región Metropolitana. La diferencia de matricular a los hijos en colegios privados sólo es significativa con respecto a la exigencia de comprar acciones. Por su parte, acceder a colegios subvencionados implica con mayor frecuencia la demostración de provenir de una familia cercana a la congregación religiosa y ser descendiente de la comunidad asociada al colegio. 


\section{Tabla III}

Modelos de regresión logística binaria de los requisitos de admisión para las escuelas (muestra general)

\begin{tabular}{|c|c|c|c|c|c|c|c|c|c|c|c|}
\hline & A & B & C & D & E & $\mathbf{F}$ & G & H & I & J & K \\
\hline \multicolumn{12}{|l|}{ Tipo de escuela } \\
\hline \multirow[t]{2}{*}{ Pública } & -0.199 & $-0.513^{* * *}$ & $-0.521^{* * *}$ & $-0.865^{\star * *}$ & $-0.924^{* * *}$ & $-1.260^{* * *}$ & $-0.792^{* * *}$ & $-1.340^{* * *}$ & $-1.071^{\star * *}$ & $-1.118^{* * *}$ & -0.192 \\
\hline & $(0.190)$ & $(0.191)$ & $(0.200)$ & $(0.188)$ & $(0.213)$ & $(0.422)$ & $(0.214)$ & $(0.360)$ & $(0.275)$ & $(0.248)$ & $(0.468)$ \\
\hline \multirow[t]{2}{*}{ Privada } & 0.199 & -0.299 & -0.210 & $-0.751^{* *}$ & $-1.095^{\star * *}$ & $-0.785^{\star}$ & -0.300 & $-0.984^{*}$ & -0.587 & -0.211 & 0.184 \\
\hline & $(0.277)$ & $(0.303)$ & $(0.365)$ & $(0.309)$ & $(0.316)$ & $(0.432)$ & $(0.319)$ & $(0.540)$ & $(0.382)$ & $(0.341)$ & $(0.447)$ \\
\hline \multicolumn{12}{|l|}{ Clase social } \\
\hline \multirow[t]{2}{*}{$\begin{array}{l}\text { Ocupaciones } \\
\text { intermedias }\end{array}$} & -0.031 & -0.217 & 0.081 & 0.028 & -0.063 & 0.512 & -0.376 & -0.286 & -0.356 & $-0.754^{* *}$ & -0.385 \\
\hline & $(0.244)$ & $(0.256)$ & $(0.293)$ & $(0.268)$ & $(0.285)$ & $(0.343)$ & $(0.283)$ & $(0.327)$ & $(0.292)$ & $(0.314)$ & $(0.463)$ \\
\hline \multirow[t]{2}{*}{$\begin{array}{l}\text { Trabajadores } \\
\text { manuales/rutinarios }\end{array}$} & -0.111 & 0.001 & 0.164 & -0.257 & 0.007 & 0.580 & 0.293 & 0.078 & -0.218 & -0.010 & 0.374 \\
\hline & $(0.268)$ & $(0.280)$ & $(0.304)$ & $(0.283)$ & $(0.319)$ & $(0.496)$ & $(0.313)$ & $(0.462)$ & $(0.374)$ & $(0.362)$ & $(0.591)$ \\
\hline \multirow[t]{2}{*}{ Nunca ha trabajado } & -0.157 & -0.341 & 0.034 & -0.196 & -0.138 & 0.622 & -0.315 & -0.107 & -0.482 & -0.598 & 0.462 \\
\hline & $(0.296)$ & $(0.305)$ & $(0.337)$ & $(0.304)$ & $(0.355)$ & $(0.570)$ & $(0.365)$ & $(0.518)$ & $(0.460)$ & $(0.414)$ & $(0.576)$ \\
\hline \multirow[t]{2}{*}{ Educación } & 0.065 & $-0.149^{*}$ & $0.152^{*}$ & -0.019 & -0.079 & -0.208 & -0.067 & -0.188 & $-0.396^{* * *}$ & -0.148 & $-0.392^{* *}$ \\
\hline & $(0.080)$ & $(0.077)$ & $(0.084)$ & $(0.076)$ & $(0.088)$ & $(0.170)$ & $(0.0918)$ & $(0.153)$ & $(0.112)$ & $(0.114)$ & $(0.184)$ \\
\hline \multirow[t]{2}{*}{ Capital social } & $0.091^{* *}$ & 0.000 & 0.022 & $0.073^{*}$ & 0.070 & 0.077 & 0.0615 & $0.198^{* * *}$ & $0.110^{* *}$ & 0.076 & $0.229^{* *}$ \\
\hline & $(0.044)$ & $(0.048)$ & $(0.049)$ & $(0.044)$ & $(0.047)$ & $(0.070)$ & $(0.048)$ & $(0.075)$ & $(0.056)$ & $(0.053)$ & $(0.096)$ \\
\hline \multirow[t]{2}{*}{ Capital cultural } & 0.046 & $0.186^{* * *}$ & $0.180^{* \star *}$ & 0.091 & $0.182^{* * *}$ & $0.279^{* * *}$ & $0.188^{* * *}$ & 0.100 & $0.179^{* *}$ & $0.233^{* * *}$ & $0.494^{* * *}$ \\
\hline & $(0.062)$ & $(0.063)$ & $(0.069)$ & $(0.065)$ & $(0.065)$ & $(0.093)$ & $(0.069)$ & $(0.089)$ & $(0.077)$ & $(0.074)$ & $(0.139)$ \\
\hline \multirow[t]{2}{*}{ Capital económico } & -0.000 & $0.003^{* * *}$ & $0.002^{* *}$ & $0.001^{* *}$ & $0.003^{* * *}$ & $0.004^{* * *}$ & $0.001^{*}$ & $0.004^{* * *}$ & $0.003^{* * *}$ & $0.002^{* *}$ & $0.003^{* *}$ \\
\hline & $(0.001)$ & $(0.001)$ & $(0.001)$ & $(0.001)$ & $(0.001)$ & $(0.001)$ & $(0.001)$ & $(0.001)$ & $(0.001)$ & $(0.001)$ & $(0.001)$ \\
\hline \multicolumn{12}{|l|}{ Identificación política } \\
\hline \multirow[t]{2}{*}{ Izquierda } & -0.015 & 0.529 & -0.201 & -0.114 & 0.445 & 0.902 & -0.556 & 0.722 & 0.553 & 0.365 & 0.097 \\
\hline & $(0.366)$ & $(0.431)$ & $(0.398)$ & $(0.373)$ & $(0.399)$ & $(0.625)$ & $(0.371)$ & $(0.562)$ & $(0.479)$ & $(0.459)$ & $(0.613)$ \\
\hline \multirow[t]{2}{*}{ Centro izquierda } & 0.220 & 0.507 & 0.510 & 0.096 & 0.213 & 0.378 & $-0.893^{* *}$ & -1.121 & 0.064 & 0.155 & -0.428 \\
\hline & $(0.394)$ & $(0.453)$ & $(0.455)$ & $(0.405)$ & $(0.438)$ & $(0.732)$ & $(0.411)$ & $(0.768)$ & $(0.547)$ & $(0.494)$ & $(0.735)$ \\
\hline \multirow[t]{2}{*}{$\begin{array}{l}\text { Sin identificación } \\
\text { política }\end{array}$} & -0.102 & -0.094 & 0.128 & -0.316 & -0.048 & 0.173 & $-0.863^{* *}$ & 0.469 & -0.081 & -0.114 & -0.153 \\
\hline & $(0.348)$ & $(0.401)$ & $(0.383)$ & $(0.342)$ & $(0.376)$ & $(0.582)$ & $(0.341)$ & $(0.503)$ & $(0.477)$ & $(0.455)$ & $(0.594)$ \\
\hline \multirow[t]{2}{*}{ Religión católica } & $-0.341^{*}$ & -0.225 & $0.455^{* *}$ & 0.299 & -0.063 & $0.740^{*}$ & $0.459^{* *}$ & 0.124 & 0.430 & $0.849^{\star * *}$ & 0.131 \\
\hline & $(0.175)$ & $(0.182)$ & $(0.187)$ & $(0.183)$ & $(0.202)$ & $(0.391)$ & $(0.214)$ & $(0.322)$ & $(0.267)$ & $(0.270)$ & $(0.403)$ \\
\hline \multirow[t]{2}{*}{ Práctica religiosa } & $0.368^{* *}$ & 0.011 & $0.326^{*}$ & 0.176 & $0.546^{\star * *}$ & -0.161 & $0.528^{* * *}$ & 0.086 & 0.204 & 0.334 & -0.038 \\
\hline & $(0.168)$ & $(0.170)$ & $(0.178)$ & $(0.173)$ & $(0.196)$ & $(0.321)$ & $(0.194)$ & $(0.288)$ & $(0.241)$ & $(0.217)$ & $(0.355)$ \\
\hline \multirow[t]{2}{*}{ Constante } & $-1.151^{* *}$ & -0.252 & -0.905 & -0.429 & $-2.054^{* * *}$ & $-4.708^{* * *}$ & -0.872 & $-2.963^{* * *}$ & $-2.268^{* * *}$ & $-2.024^{* * *}$ & $-4.643^{* * *}$ \\
\hline & $(0.519)$ & $(0.550)$ & $(0.563)$ & $(0.510)$ & $(0.606)$ & $(1.000)$ & $(0.577)$ & $(0.731)$ & $(0.777)$ & $(0.746)$ & $(1.039)$ \\
\hline Observaciones & 800 & 800 & 800 & 800 & 800 & 800 & 800 & 800 & 800 & 800 & 800 \\
\hline Pseudo R-cuadrado & 0.0737 & 0.105 & 0.127 & 0.126 & 0.189 & 0.248 & 0.137 & 0.251 & 0.198 & 0.204 & 0.310 \\
\hline
\end{tabular}




\section{Tabla IV}

Modelos de regresión logística binaria de los requisitos de admisión para las escuelas (muestra alta renta)

\begin{tabular}{|c|c|c|c|c|c|c|c|c|c|c|c|c|}
\hline & A & B & C & D & E & $\mathbf{F}$ & G & H & I & J & K & L \\
\hline \multicolumn{13}{|l|}{ Tipo de escuela } \\
\hline \multirow[t]{2}{*}{ Privada } & -0.459 & $-1.877^{* *}$ & $* 0.453$ & -0.0846 & $6-0.219$ & $-0.951^{* *}$ & 0.439 & $-0.866^{* *}$ & 0.532 & -0.0495 & -0.428 & $2.005^{* * *}$ \\
\hline & $(0.301)$ & $(0.369)$ & $(0.514)$ & $(0.407)$ & $(0.321)$ & $(0.406)$ & $(0.351)$ & $(0.394)$ & $(0.330)$ & $(0.332)$ & $(0.370)$ & $(0.439)$ \\
\hline \multicolumn{13}{|l|}{ Clase social } \\
\hline \multirow[t]{2}{*}{ Ocupaciones intermedias } & $-0.841^{* *}$ & * 0.0868 & $-1.684^{* * *}$ & ${ }^{*}-0.855^{*}$ & -0.200 & $-1.345^{*}$ & -0.499 & -0.741 & $-0.925^{* *}$ & -0.376 & $-1.627^{* * *}$ & $*-1.805^{\star * *}$ \\
\hline & $(0.428)$ & $(0.432)$ & $(0.642)$ & $(0.455)$ & $(0.406)$ & $(0.712)$ & $(0.493)$ & $(0.485)$ & $(0.443)$ & $(0.423)$ & $(0.525)$ & $(0.528)$ \\
\hline \multirow[t]{2}{*}{ Nunca ha trabajado } & -0.616 & 0.164 & $-1.617^{* *}$ & -0.493 & 0.032 & -0.851 & -0.381 & $-1.218^{* *}$ & -0.307 & -0.259 & -0.525 & $-1.582^{* * *}$ \\
\hline & $(0.444)$ & $(0.475)$ & $(0.696)$ & $(0.519)$ & $(0.491)$ & $(0.699)$ & $(0.550)$ & $(0.581)$ & $(0.497)$ & $(0.491)$ & $(0.516)$ & $(0.592)$ \\
\hline \multirow[t]{2}{*}{ Educación } & $0.531^{* *}$ & $0.461^{* *}$ & -0.163 & 0.104 & $0.651^{* *}$ & $1.289^{* *}$ & 0.001 & -0.274 & $0.846^{* * *}$ & 0.285 & 0.467 & -0.115 \\
\hline & $(0.240)$ & $(0.220)$ & $(0.214)$ & $(0.242)$ & $(0.273)$ & $(0.648)$ & $(0.231)$ & $(0.355)$ & $(0.315)$ & $(0.232)$ & $(0.343)$ & $(0.341)$ \\
\hline \multirow[t]{2}{*}{ Capital social } & -0.0261 & -0.0372 & $0.291^{* *}$ & $0.203^{* *}$ & -0.023 & -0.069 & $0.207^{* *}$ & 0.083 & 0.130 & 0.021 & -0.035 & $0.155^{*}$ \\
\hline & $(0.081)$ & $(0.079)$ & $(0.117)$ & $(0.079)$ & $(0.073)$ & $(0.115)$ & $(0.091)$ & $(0.095)$ & $(0.086)$ & $(0.086)$ & $(0.089)$ & $(0.093)$ \\
\hline \multirow[t]{2}{*}{ Capital cultural } & 0.056 & $0.231^{* *}$ & 0.073 & $0.186^{*}$ & 0.070 & 0.136 & -0.045 & 0.158 & 0.003 & -0.032 & $0.316^{* *}$ & -0.087 \\
\hline & $(0.0959$ & (0.0963) & $(0.149)$ & $(0.102)$ & $(0.0923)$ & $(0.193)$ & $(0.105)$ & $(0.147)$ & $(0.104)$ & $(0.0952)$ & $(0.149)$ & $(0.117)$ \\
\hline \multirow[t]{2}{*}{ Capital económico } & -0.001 & $0.003^{* * *}$ & $0.003^{*}$ & -0.000 & 0.002 & $0.005^{\star *}$ & $0.002^{*}$ & $0.009^{* * *}$ & $0.002^{*}$ & $0.003^{* *}$ & 0.002 & 0.002 \\
\hline & $(0.001)$ & $(0.001)$ & $(0.002)$ & $(0.001)$ & $(0.001)$ & $(0.002)$ & $(0.001)$ & $(0.002)$ & $(0.001)$ & $(0.001)$ & $(0.002)$ & $(0.002)$ \\
\hline \multicolumn{13}{|l|}{ Identificación política } \\
\hline \multirow[t]{2}{*}{ Izquierda } & -0.211 & -0.198 & 0.851 & -0.676 & -0.303 & 1.026 & -0.825 & 0.041 & -0.239 & -0.880 & 0.117 & -0.080 \\
\hline & $(0.518)$ & $(0.560)$ & $(1.201)$ & $(0.655)$ & $(0.638)$ & $(0.842)$ & $(0.622)$ & $(0.500)$ & $(0.603)$ & $(0.637)$ & $(0.699)$ & $(0.620)$ \\
\hline \multirow[t]{2}{*}{ Centro izquierda } & 0.0377 & -0.001 & -0.877 & -0.092 & 0.038 & -1.132 & -0.540 & 0.415 & -0.378 & -0.307 & $-2.399^{* * *}$ & $*-2.636^{* * *}$ \\
\hline & $(0.541)$ & $(0.568)$ & $(0.830)$ & $(0.653)$ & $(0.506)$ & $(0.832)$ & $(0.599)$ & $(0.593)$ & $(0.596)$ & $(0.573)$ & $(0.803)$ & $(0.830)$ \\
\hline \multirow[t]{2}{*}{ Centro derecha } & -0.183 & 0.734 & -1.042 & -0.532 & -0.629 & 0.566 & -0.821 & 0.533 & 0.636 & $-1.126^{* *}$ & * 0.347 & $-1.321^{* *}$ \\
\hline & $(0.567)$ & $(0.622)$ & $(0.893)$ & $(0.689)$ & $(0.545)$ & $(0.637)$ & $(0.545)$ & $(0.618)$ & $(0.639)$ & $(0.486)$ & $(0.691)$ & $(0.668)$ \\
\hline \multirow[t]{2}{*}{ Sin identificación política } & -0.583 & -0.398 & 0.454 & 0.459 & -0.526 & 0.301 & -0.040 & $0.889^{* *}$ & -0.259 & $-0.872^{* *}$ & * -0.034 & -0.461 \\
\hline & $(0.380)$ & $(0.435)$ & $(0.659)$ & $(0.560)$ & $(0.380)$ & $(0.448)$ & $(0.452)$ & $(0.419)$ & $(0.459)$ & $(0.412)$ & $(0.461)$ & $(0.484)$ \\
\hline \multirow[t]{2}{*}{ Religión católica } & $0.762^{* *}$ & $0.915^{* *}$ & 0.276 & 0.436 & -0.210 & -0.078 & $1.027^{* *}$ & $-0.947^{* *}$ & $0.829^{* *}$ & 0.192 & 0.132 & 0.452 \\
\hline & $(0.363)$ & $(0.438)$ & $(0.654)$ & $(0.376)$ & $(0.381)$ & $(0.539)$ & $(0.408)$ & $(0.395)$ & $(0.362)$ & $(0.429)$ & $(0.433)$ & $(0.434)$ \\
\hline \multirow[t]{2}{*}{ Práctica religiosa } & 0.018 & $0.760^{* *}$ & -0.947 & 0.573 & $0.974^{* * *}$ & $1.878^{* * *}$ & 0.500 & $1.159^{* * *}$ & $0.691^{*}$ & $0.966^{* * *}$ & *0.822 & $1.070^{* *}$ \\
\hline & $(0.346)$ & $(0.338)$ & $(0.589)$ & $(0.391)$ & $(0.362)$ & $(0.665)$ & $(0.378)$ & $(0.392)$ & $(0.374)$ & $(0.366)$ & $(0.545)$ & $(0.470)$ \\
\hline \multirow[t]{2}{*}{ Constante } & $-2.629^{* \star}$ & * $-4.435^{\star *}$ & $* 0.619$ & -1.117 & $-4.705^{* * \star}$ & * $-10.850^{* * *}$ & $-2.856^{* *}$ & ${ }^{*}-6.064^{* * *}$ & ${ }^{*}-7.339^{* *}$ & * $-2.804^{* *}$ & ${ }^{*}-5.139^{* * *}$ & ${ }^{*}-3.880^{* *}$ \\
\hline & $(1.124)$ & $(1.155)$ & $(1.288)$ & $(1.138)$ & $(1.282)$ & (3.170) & $(1.189)$ & $(2.040)$ & $(1.671)$ & $(1.154)$ & $(1.671)$ & $(1.676)$ \\
\hline Observaciones & 400 & 400 & 400 & 400 & 400 & 400 & 400 & 400 & 400 & 400 & 400 & 400 \\
\hline Pseudo R-cuadrado & 0.124 & 0.254 & 0.361 & 0.249 & 0.217 & 0.367 & 0.193 & 0.374 & 0.247 & 0.164 & 0.290 & 0.292 \\
\hline
\end{tabular}

Nota: Errores estándar robustos. ${ }^{* * *} p<0.01,{ }^{* *} p<0.05,{ }^{*} p<0.1$. 
A diferencia de la muestra general, la variable clase social se muestra como un factor sumamente importante en el cono de alta renta, sobre todo en lo relacionado con los mecanismos de selección más exclusivos, tanto de tipo económico como social y religioso. Los padres que ocupan puestos de gerentes o profesionales tienen más probabilidades de matricular a sus hijos en colegios donde la selección se produce mediante la solicitud de certificado de remuneraciones, la compra de acciones, la demostración de la procedencia de una familia cercana a la congregación religiosa del colegio y la presentación de cartas de recomendación.

Al igual que el nivel educacional, los capitales social y cultural se muestran como predictores significativos sólo en algunos casos, especialmente en requisitos de entrada más comunes, como sucede, por ejemplo, con el examen escrito. En todo caso, también debemos notar que aparecen relacionados con requerimientos más exclusivos. Mientras un mayor capital social se asocia positivamente con el requisito de compra de acciones, el capital cultural tiene un efecto positivo en la solicitud de cartas de recomendación. No obstante la relevancia reconocida en ocasiones a los capitales previos, el capital económico tiene un efecto positivo y transversal en relación con la mayoría de los criterios de selección. Cabe destacar especialmente su impacto sobre requisitos de tipo social y religioso, como el certificado de bautizo o matrimonio por la Iglesia, provenir de una familia cercana a la congregación religiosa del colegio y ser descendiente de la comunidad asociada al colegio.

En general, la identificación política de los padres no se muestra como un predictor significativo de la solicitud de requisitos por parte de las escuelas, tal como ocurría con la muestra general. No obstante, se observan algunas diferencias respecto de requisitos más distintivos, específicamente cuando los padres declaran una identificación con la derecha. En este sentido, mientras los padres que se posicionan políticamente en el centro-derecha, junto con aquellos que no muestran una preferencia política, presentan en menor medida el certificado de bautizo o matrimonio por la Iglesia, los que se identifican con el centro-izquierda tienen menos probabilidad de enfrentar los criterios más selectivos, la solicitud de cartas de recomendación y la compra de acciones.

Un hallazgo particularmente novedoso se reporta en función del comportamiento religioso de los padres localizados en el cono de alta renta. Por un lado, los padres que se declaran católicos tienen más probabilidades de matricular a sus hijos en colegios que tienen requisitos de entrada más comunes, como la evaluación de educación preescolar, el certificado de notas del establecimiento anterior y el matrimonio civil de los padres, aunque también mediante criterios más selectivos, como ser des- cendiente de la comunidad asociada al colegio. Por otro lado, cuando nos adentramos en los criterios de entrada que representan mayor exclusividad y distinción, es la práctica religiosa la que tiene un mayor impacto. Esto no sólo ocurre, como podría esperarse, respecto de criterios de tipo social y religioso (ser descendiente de la comunidad asociada al colegio, provenir de una familia cercana a la congregación religiosa del colegio y el certificado de bautizo o matrimonio por la Iglesia), sino también de carácter económico (certificado de remuneraciones y compra de acciones).

En suma, dentro del grupo de alta renta se observan mecanismos de segregación que combinan una alta posición en la estructura social (ocupaciones profesionales y ejecutivas) y la mayor disponibilidad relativa de recursos económicos, junto a disposiciones como la identificación política con la derecha y religiosa con la Iglesia Católica, junto a la práctica religiosa. Estos dos últimos elementos constituyen lo que podríamos denominar un capital religioso católi$c o$. No en vano, este último recurso produce algunas de las mayores diferencias y barreras dentro de la clase alta (Méndez y Gayo 2019).

\section{Discusión}

Las familias de la capital chilena se han venido enfrentando comúnmente en las últimas décadas a la selección que hacen los colegios de sus postulantes, aunque ello a menudo sea ilegal (Carrasco, Gutiérrez y Flores 2017). Los doce criterios que fueron incorporados en la encuesta a las dos muestras utilizadas confirman la amplitud de los requisitos de entrada en las instituciones escolares, siendo más frecuentes en los colegios del barrio alto privados y, sobre todo, subvencionados. Por lo tanto, el modelo de elección de colegio es igualmente, y quizás con la misma intensidad, un modelo de selección de las familias postulantes. Dicho de otra forma, hablamos de un proceso de diferenciación que implica la inversión de recursos y el despliegue de ciertas competencias por parte de las familias, cuya finalidad es tener un mejor desempeño en el proceso selectivo (Carrasco, Donoso y Mendoza 2016a). La selección, entonces, aparece como la dialéctica resultante de poder elegir y ser elegido, de poder aprovechar la oportunidad de maximizar la distinción de clase, de producir y legitimar activamente las diferencias sociales originales (Kaufman 2005; Lareau 2011; Maloutas 2007). El aporte de este estudio se centra en entender qué tipo de familias está capacitada para superar los obstáculos que deben enfrentar para conseguir el acceso al colegio que desea.

Nuestro estudio demuestra que la capacidad de las familias de clase media para superar las barreras de acceso está socialmente estructurada, tal 
como ha sido precisado en investigaciones anteriores (Ball 2003; Benson, Bridge y Wilson 2015; Burgess et al. 2015; Kimelberg 2014; Carrasco, Gutiérrez y Flores 2017). En lo que corresponde a la muestra general, la mayor acumulación de los capitales social, cultural y, sobre todo, económico ofrece ventajas para la superación de los requisitos de acceso. Asimismo ocurre con la identificación con la fe católica y la práctica religiosa de la misma naturaleza. En términos generales, podríamos decir que algo similar sucede en el área de altos ingresos. No obstante, hay algunos elementos diferenciales propios de este último caso. En primer lugar, la importancia de los colegios públicos es residual, lo que expone a una gran mayoría de las familias a la necesidad de superar las barreras de entrada. En segundo lugar, aparecen importantes diferencias de clase, lo que muestra no sólo la desigualdad existente en sectores de alta renta, sino, igualmente, las ventajas comparativas de la clase de profesionales y directivos frente a sus competidores locales. Por lo tanto, también en este sector los colegios contribuyen a reforzar la desigualdad de origen o, lo que es lo mismo, a transmitir los capitales o las ventajas de padres a hijos a través del sistema educativo. En otros términos, los colegios privados juegan un papel central en la reproducción de fragmentos particulares de clase. En tercer lugar, aparece nuevamente la relevancia de la identificación y las prácticas religiosas, pero esta vez destacando la mayor importancia de la práctica, sobre todo en aspectos en los que no tenía particular relevancia en la muestra general, como son: el ser descendiente de una comunidad asociada al colegio, las remuneraciones, el bautizo o el matrimonio por la Iglesia y, por último y de manera más exclusiva, la compra de acciones. En un sentido inverso, cuando Flores y Carrasco (2016) hablaban del factor religioso, era para destacar la propensión de las personas de religión evangélica a elegir colegios de menor rendimiento relativo. Más cerca de los resultados de nuestra investigación, el estudio realizado por Andreotti, Le Galès y Moreno (2015) sobre las clases medias altas en tres ciudades europeas muestra que, cuando estos grupos no viven en barrios segregados, junto con otros vecinos similares a ellos en términos sociales, económicos y étnicos, la preferencia es el colegio católico subvencionado, ya que éste exige cierta selectividad y, con ello, garantiza que estas familias puedan también tener cierto control sobre la exposición que sus hijos tienen a la diversidad. Esto podría estar pasando en Santiago de Chile en un contexto de mayor segregación.

\section{Conclusiones}

Este artículo muestra cómo la elección de colegios con rasgos particulares, identificados aquí principalmente a través de un amplio conjunto de requisitos de entrada, ha operado en Santiago de Chile favoreciendo a las familias católicas de clase media alta. Los padres y madres de este grupo socioeconómico han tenido en la capacidad de elegir una aliada en el proceso de su formación histórica como una clase distintiva. Pero ello probablemente hubiese sido insuficiente sin la política complementaria de los colegios, los cuales, de forma legal o ilegal (Carrasco, Gutiérrez y Flores 2017), han mantenido prácticas de selección basadas en características de los postulantes y sus familias, sea ello por su eficacia práctica asociada al logro educativo, sea ello por su relevancia simbólica en este medio social (Carrasco, Falabella y Tironi 2016b). Nosotros argüimos que es la imbricación de ambos procesos, electivo escolar y selectivo familiar, lo que constituye el mecanismo escolar como un dispositivo social encargado de la transmisión de las posiciones de clase. Las familias de clase media alta santiaguinas necesitan un colegio adecuado no sólo como un lugar avanzado de aprendizaje de conocimientos, sino igualmente como una institución ritual que consagra unos destinos y degrada otros definitivamente. En este juego de inclusión y exclusión, de logro y fracaso permanente, las familias deben poner en evidencia recursos clave para su supervivencia, como son los capitales e igualmente las prácticas y creencias adecuadas. Sin esta actuación, los meros valores o las buenas intenciones serían, muy probablemente, insuficientes. En este sentido, el modelo de school choice ha devenido en una institución que ha adaptado sus reglas a la estructura social en la cual se ha insertado, fortaleciendo la reproducción que demandan los miembros de la clase media alta.

Finalmente, de nuestro estudio emerge, asimismo, la significación clave de la práctica religiosa como un comportamiento eficaz para favorecer la reproducción de clase, a través de sus positivos efectos en la superación de las barreras de entrada en los colegios más prestigiosos del sistema educativo. Ser católico practicante ha venido siendo un requisito habitual en los colegios de mayor selectividad del sistema escolar, constituyéndose, por tanto, esta actividad en un elemento estratégico dentro del repertorio de prácticas de las familias más privilegiadas del país. Esto viene acompañado de la exclusión que se ha producido principalmente con base en la renta o el ingreso familiar, lo que nuevamente ha favorecido a la clase media alta capitalina.

\section{Agradecimientos}

Esta investigación ha sido apoyada por el Fondo Nacional de Desarrollo Científico y Tecnológico, proyecto Fondecyt Regular 1140136; y también por el Centro de Estudios de Conflicto y Cohesión Social - COES, Proyecto CONICYT/FONDAP/15130009. 


\section{NotAs}

[1] Podríamos decir que esta concordancia social entre familia y escuela es un ideal implícito sobre el que funciona el sistema (Rivera y Milicic 2006). Si bien estos autores problematizan casos de familias de bajos recursos en los que dicho ajuste frecuentemente no se produce.

[2] Por momento de la elección queremos hacer referencia a la toma efectiva y concreta de la decisión, cuando esta ya se ha producido y se enfrenta con obstáculos o requisitos específicos. No abordamos la formación de la decisión, lo que tiene que ver con un proceso evaluativo en cuya base están los valores y cuestiones prácticas varias (distancia, costo, entre otras), tema al que han dedicado esfuerzos otros investigadores (Carrasco, Donoso y Mendoza 2016a).

\section{ReferenCIAS BibliogRÁficas}

Agostini, C.A., D. Hojman, A. Román y L. Valenzuela. 2016. "Segregación residencial de ingresos en el Gran Santiago, 1992-2002: una estimación robusta", EURE 42(127): 159-184. http://dx.doi.org/10.4067/S025071612016000300007

Andreotti, A., P. Le Galès, F. J. Moreno. 2015. Globalised Minds, Roots in the City: Urban Upper-middle Classes in Europe. West Sussex: Wiley-Blackwell.

Bacqué, M., G. Bridge., M. Benson, T. Butler, E. Charmes, Y. Fijalkow, E. Jackson, L. Launay y S. Vermeersch. 2015. The Middle Classes and the City. A Study of Paris and London. London: Palgrave, Macmillan.

Ball, S. 2003. Class Strategies and the Education Market: The Middle Classes and Social Advantage. London: Routledge. https://doi.org/10.4324/9780203218952

Bellei, C. 2007. "Expansión de la educación privada y mejoramiento de la educación en Chile. Evaluación a partir de la evidencia". Rev. Pensamiento Educativo 40(1): 285-311.

Benson, M., G. Bridge y D. Wilson. 2015. "School choice in London and Paris. A comparison of middle-class strategies". Social Policy \& Administration 49(1): 24-43. https://doi.org/10.1111/spol.12079

Borman, G., y M. Dowling, M. 2010. "Schools and inequality: A multilevel analysis of Coleman's equality of educational opportunity data". Teachers College Record 112(5): 1201-1246.

Boterman, W. 2013 "Dealing with diversity: Middle-class family households and the issue of 'black' and 'white' schools in Amsterdam". Urban Studies 50(6): 1130-1147. https://doi.org/10.1177/0042098012461673

Bourdieu, P. y J. Passeron. 1990. Reproduction in Education, Society and Culture. London: Sage.

Burgess, S., E. Greaves, A. Vignoles, y D. Wilson. 2015. "What parents want: School preferences and school choice". The Economic Journal 125(587): 1262-1289. https:// doi.org/10.1111/ecoj.12153

Carrasco, A., A. Falabella y M. Mendoza. 2015. "School Choice in Chile as a Sociocultural Practice. An Ethnographic Inquiry". Pp. 245-266 en Contrasting Dynamics in Education Politics of Extremes. School Choice in Chile and Finland., edited by P. Seppänen, A. Carrasco, M. Kalalahti, R. Rinne y H. Simola. Rotterdam: Sense Publishers.
Estudios como el de Puga (2011) subrayan el carácter selectivo del acceso a los colegios subvencionados, pero no estudian las características de la selección. Sobre esto se avanza en investigaciones como las de Carrasco, Gutiérrez y Flores 2017, si bien esta ofrece información sobre los colegios entregada por los profesores jefe y no por los apoderados, como es la que nosotros analizamos en el presente trabajo. Igualmente, por una vía u otra, se puede observar que, efectivamente, los criterios de selección están asociados a realidades escolares desiguales.

[3] Unidad de Estadísticas del Centro de Estudios del Ministerio de Educación. Sitio web: http://datosabiertos. mineduc.cl/

Carrasco, A., A. Donoso y M. Mendoza. 2016a: "La dimensión ético-política de la elección de escuela: dilemas en familias chilenas de élite", en Mercado escolar y oportunidad educacional. Libertad, diversidad y desigualdad, editado por J. Corvalán, A. Carrasco y J.E. García-Huidobro. Santiago de Chile: Ed. Universidad Católica de Chile.

Carrasco, A., A. Falabella y M. Tironi, M. 2016b: "Sociologizar la construcción de preferencias: elección escolar como práctica sociocultural", en Mercado escolar y oportunidad educacional. Libertad, diversidad y desigualdad, editado por J. Corvalán, A. Carrasco y J.E. García-Huidobro. Santiago de Chile: Ed. Universidad Católica de Chile.

Carrasco, A., G. Gutiérrez y C. Flores. 2017: "Failed regulations and school composition: selective admission practices in Chilean primary schools", Journal of Education Policy 32(5): 642-672. https://doi.org/10.1080/0 2680939.2017.1312549

Chubb, J. y T. Moe. 1990. Politics, Markets, and America's Schools. Washington DC: Brookings Institution Press.

Contreras, D., P. Sepúlveda y S. Bustos. 2010. "When schools are the ones that choose: The effects of screening in Chile". Social Science Quarterly 91(5): 1349-1368. https://doi.org/10.1111/j.1540-6237.2010.00735.x

Elacqua, G. 2012. "The impact of school choice and public policy on segregation: Evidence from Chile". International Journal of Educational Development 32(3): 444-453. https://doi.org/10.1016/j.ijedudev.2011.08.003

Erickson, B. H. (1996). "Culture, class, and connections". American journal of Sociology, 102(1): 217-251. https://doi. org/10.1086/230912

Flap, H. y E. Boxman. 2001 "Getting Started: The Influence of Social Capital on the Start of the Occupational Career". Pp. 159-84 en Social Capital: Theory and Research, editado por N. Lin, K. Cook y R. S. Burt. New York: Aldine de Gruyter.

Flores, C. y A. Carrasco. 2016. "Elegir lo que hay: ¿cuentan las familias en sus barrios con una oferta de escuelas que responda a sus preferencias?". Pp. 151-187 en Mercado escolar y oportunidad educacional. Libertad, diversidad y desigualdad, editado por J. Corvalán, A. Carrasco y J.E. García-Huidobro. Santiago de Chile: Ed. Universidad Católica de Chile. 
Gaag, M. van der, T. Snijders y H. Flap. 2008). "Position Generator measures and their relationship to other social capital measures". Pp. 27-49, en Social capital: advances in research, editado por N. Lin y B. Erickson. Oxford: Oxford University Press. https://doi.org/10.1093/acprof :oso/9780199234387.003.0011

Gessaghi, V. y A. Méndez. 2015. "Elite Schools in Buenos Aires: The Role of Tradition and School Social Networks in the Production and Reproduction of Privilege". Pp. 43-55 en Elites, Privilege and excellence: The National and Global Redefinition of Educational Advantage: World Yearbook of Education 2015, editado por A. van Zanten, S. Ball y B. Darchy-Koechlin. London: Routledge.

Hastings, J. S. y J. M. Weinstein. 2007. "Information, School Choice, and Academic Achievement: Evidence from Two Experimen-ts". NBER Working Paper n 13623. National Bureau of Economic Research. https://doi. org/10.3386/w13623

Hsieh, C. y M. Urquiola. 2006. "The effects of generalized school choice on achievement and stratification: Evidence from Chile's voucher program". Journal of Public Economics 90(8-9): 1477-1503. https://doi. org/10.1016/j.jpubeco.2005.11.002

Kaufman, P. 2005. "Middle-class social reproduction: The activation and negotiation of structural advantages". Sociological Forum 20(2): 245-270.

Kimelberg, S .2014. "Beyond test scores: Middle-class mothers, cultural capital, and the evaluation of urban public schools". Sociological Perspectives 57(2): 208228. https://doi.org/10.1177/0731121414523398

Klees, S. 2008. "A quarter century of neoliberal thinking in education: Misleading analyses and failed policies". Globalisation, Societies and Education 6(4): 311-348. https://doi.org/10.1080/14767720802506672

Lareau, A. (2011). Unequal childhoods. Class, Race and Family Life. Los Angeles: University California Press.

Lin, N. (2008). "A network theory of social capital". Pp. 50-69 en The Handbook of Social Capital, editado por D. Castiglione, J. van Deth y G. Wolleb. Oxford University Press, pp.

Lubienski, C., P. Weitzel y S. Lubienski. 2009 "Is there a 'consensus' on school choice and achievement? Advocacy research and the emerging political economy of knowledge production". Educational Policy 23(1): 161193. https://doi.org/10.1177/0895904808328532

Madero, C. e I. Madero. 2012. "Elección escolar y selección estudiantil en el sistema escolar chileno ¿Quién elige a quién? El caso de la educación católica". Revista Mexicana de Investigación Educativa 17(55): 1267-1295.

Malmberg, B., E. Andersson y Z. Bergsten. 2014. "Composite geographical context and school choice attitudes in Sweden: A study based on individually defined, scalable neighborhoods". Annals of the Association of American Geographers, 104(4): 869-888. https://doi.org/10 $.1080 / 00045608.2014 .912546$

Maloutas, T. 2007. "Middle class education strategies and residential segregation in Athens". Journal of Education Policy 22(1): 49-68. https://doi. org/10.1080/02680930601065742

Mau, S. 2015. Inequality, Marketization and the Majority Class. Why Did the European Middle Classes Accept Neo-Liberalism? New York: Palgrave Macmillan.
Méndez, M.L. y M. Gayo. 2019. Upper Middle Class Social Reproduction. Wealth, Schooling and Residential Choice in Chile. Cham (Switzerland): Palgrave MacMillan.

Mizala, A. y F. Torche. 2012. "Bringing the schools back in: The stratification of educational achievement in the Chilean voucher system". International Journal of Educational Development 32(1): 132-144. https://doi.org/10.1016/j. ijedudev.2010.09.004

Moya, E. y J. Hernández. 2014. "El rol de los colegios de elite en la reproducción intergeneracional de la elite chilena". Revista Austral de Ciencias Sociales 26: 59-82. https:// doi.org/10.4206/rev.austral.cienc.soc.2014.n26-04

Musset, P. 2012. "School choice and equity: Current policies in OECD countries and a literature review". OECD Education Working Paper 66, OECD Publishing.

Oberti, M. 2005. "Différentiation sociale et scolaire du territoire: inégalités et configurations locales". Sociétés Contemporaines 59/60: 13-42. https://doi.org/10.3917/soco.059.0013

Otero, G., R. Carranza, R y D. Contreras. 2017. “'Neighbourhood effects' on children's educational achievement in Chile: The effects of inequality and polarization". Environment and Planning A, 49(11), 2595-2618. https:// doi.org/10.1177/0308518X17731780

Puga, I. 2011. "Escuela y estratificación social en Chile: ¿Cuál es el rol de la municipalización y la educación particular subvencionada en la reproducción de la desigualdad social?" Estudios Pedagógicos 37(2): 213-232. https://doi.org/10.4067/S0718-07052011000200013

Raveaud, M. y A. van Zanten. 2007 "Choosing the local school: middle-class parents' values and social and ethnic mix in London and Paris". Journal of Education Policy, 22(1):107-124. https://doi. org/10.1080/02680930601065817

Raczynski, D. y M. Hernández. 2011. "Elección de colegio, imágenes, valoraciones y conductas de las familias y segregación escolar". Santiago de Chile: Asesorías para el Desarrollo.

Reay D., G. Crozier y D. James. 2001. White Middle Class Identities and Urban Schooling. London: Palgrave.

Rivera, M. y N. Milicic. 2006. "Alianza familia-escuela: Percepciones, creencias, expectativas y aspiraciones de padres y profesores de enseñanza general básica". Psykhe 15(1): 119-135. https://doi.org/10.4067/S071822282006000100010

Ryan, J. y M. Heise. 2002. "The political economy of school choice". The Yale Law Journal 111(8): 2043-2136. https://doi.org/10.2307/797643

Thieme, C., D. Prior y E. Tortosa-Ausina. 2013. "A multilevel decomposition of school performance using robust nonparametric frontier techniques". Economics of Education Review 32: 104-121. https://doi.org/10.1016/j. econedurev.2012.08.002

Thieme, C. y E. Treviño. 2011. "School choice and market imperfections: Evidence from Chile". Education and Urban Society 45(6): 635-657. https://doi. org/10.1177/0013124511413387

Verger, A., X. Bonal y A. Zancajo. 2016. "What are the role and impact of public-private partnerships in education? A realist evaluation of the Chilean education quasi-market". Comparative Education Review 60(2): 223-248. https://doi.org/10.1086/685557

Weis, L. 2011. The Way Class Works: Readings on School, Family, and the Economy. New York: Routledge. 
MODESTO GAYO es profesor asociado de la Escuela de Sociología de la Universidad Diego Portales (Chile). Su trabajo, enfocado en el comportamiento político de las clases medias y también en las prácticas culturales, ha sido publicado y reconocido en revistas internacionales. Es coautor del libro Culture, Class, Distinction (Routledge, 2009), Upper Middle Class Social Reproduction. Wealth, Schooling and Residential Choice in Chile (Palgrave MacMillan, 2019), Fields, Capital, Habitus: Australian Culture, Inequalities, and Social Divisions (Routledge, 2020) y autor del libro Ideología, moralidades y reproducción social. Una introducción a la sociología de la cultura (Ed. LaPala, Santiago de Chile, 2017).

GABRIEL OTERO CABROL es candidato a Doctor en Ciencias Sociales, Institute for Social Science Research (AISSR), University of Amsterdam. Patrocinado de la línea Geografías del Conflicto del Centro de Estudios de Conflicto y Cohesión Social (COES). Sociólogo de la Universidad Diego Portales y magíster en Análisis Sistémico Aplicado a la Sociedad de la Universidad de Chile. Sus temas de interés son: desigualdades, capital social, estudios urbanos y resultados educativos.

MARÍA LUISA MÉNDEZ es investigadora principal de la línea Geografías del Conflicto del COES, directora y académica de la Escuela de Sociología de la Universidad Diego Portales. Doctora en Sociología por la Universidad de Manchester del Reino Unido; magíster en Estudios Culturales y en Antropología y Desarrollo. Actualmente es investigadora principal del proyecto Fondecyt Regular № 1140136, de 2014 a 2018: "Clase media alta en Chile hoy: sobre las viejas y nuevas barreras, prácticas y costos de la reproducción de la posición de clase". Sus temas de investigación incluyen: aspectos subjetivos de la movilidad y estratificación social; construcción de pertenencia en barrios urbanos; conflictos urbanos. Es co-autora del libro Upper Middle Class Social Reproduction. Wealth, Schooling and Residential Choice in Chile (Palgrave MacMillan, 2019). 